ISSN: 2162-3104 Print/ ISSN: 2166-3750 Online

Volume 8, Issue 4 (2018), pp. 1914-1925

(C) Journal of International Students

http://jistudents.org/

doi: $10.5281 /$ zenodo. 1472920

\title{
Study Abroad Objectives and Satisfaction of International Students in Japan
}

\author{
Matthias Hennings \\ Kwansei Gakuin University, Japan \\ Shin Tanabe \\ Kwansei Gakuin University, Japan
}

\begin{abstract}
Many Japanese universities have created short-term study abroad programs with the aim of offering a satisfying study abroad experience to international students. Based on a survey of 131 international students, this paper analyzes these students' objectives and their relation to student satisfaction. As the results show, many students regard their experience of living in Japan as more important than their academic pursuits. Furthermore, for students with prior knowledge of Japanese, improving language skills tends to result in higher satisfaction, while for students who do not speak the local language, achieving cross-cultural skills is a major factor for having a satisfying experience.
\end{abstract}

Keywords: international students, Japan, objectives, satisfaction, higher education

Confronted with declining numbers of domestic students, a growing number of Japanese universities have made concerted efforts to attract more international students. Due to a reluctance of traditional faculties to change their domestic focus and integrate international content into curriculums, however, many of these universities are struggling to become more international and accommodate foreign students. Against this background, numerous Japanese universities have placed priority on revamping and enhancing short-term exchange programs as one way to increase international students (Lassegard, 2016). In addition to Japanese language classes, most of these programs also offer English-mediated courses in the humanities and social sciences with a focus on Japanese culture and society. Although there has been some criticism about English as a medium of instruction, it is seen as necessary for increasing the number of international students and facilitating partnerships with overseas institutions (Jon \& Kim, 2011). To establish such partnerships, many universities have been making use of faculty connections and actively seeking student exchange agreements on an inter-university level. Consequently, competition for such agreements has intensified as more universities attempt to establish overseas partnerships and recruit international students (Lassegard, 2016).

Surprisingly, however, little research has been conducted on the objectives of international exchange students for studying in Japan under such partnership agreements. 
Therefore, the aim of this paper is to determine those objectives, particularly what international students expect to learn and gain during their stay in Japan, and to examine the extent to which those objectives have been achieved and how they contribute to students' satisfaction with their study abroad experience, based on a survey of 131 international students at a private university in Japan. To provide contextual background, this paper begins with a brief overview of the Japanese government's initiatives, which are regarded as important pull factors for attracting international students to Japan (Aleles, 2015). That is followed by an explanation of the survey design and methodology, an analysis of the survey results, and a summary and conclusion. We hope that university administrators and educators will find this information useful when developing short-term study abroad programs that aim to meet the expectations of international students and provide them with a satisfying study abroad experience.

\section{LITERATURE REVIEW}

Push and pull factors of international student mobility have been well documented in the existing literature (e.g. Mazzarol \& Soutar, 2002, Agarwal et al., 2008, Choudaha \& De Wit, 2014, Caruso \& De Wit, 2015). In the Japanese context, Shimauchi (2014) and Aleles (2015) identified the ability to study in English while living in Japan, availability of financial assistance, affordability of study programs, and interest in Japanese culture as important pull factors for international students coming to Japan. Only a few studies, however, have documented what those students expect to learn and gain during their stay in Japan, and how those objectives are related to their satisfaction with the study abroad experience. For example, Tamaoka et al. (2003) found that international students were less satisfied with their study abroad experience when their objectives of learning in Japan did not match the curriculum provided by the Japanese university. This is in line with the later findings of a study by Asare-Nuamah (2017), which observed the impact of course content on student satisfaction, and by Perez-Encinas et al. (2018), which revealed the importance of a valuable university experience and competent teaching for international students. These studies point to the benefits of developing internationalized curricula and well-organized courses to meet the needs of international students. Nevertheless, none of these studies provided details of students' study objectives when studying abroad and the development of respective courses and curricula. In a more detailed study, Sato (2011) analyzed factors that explain a positive program evaluation among international exchange students in Japan and found that the quality of Japanese language classes is crucial for European and Australian students, while activities such as field trips matter most to students from North America. Although these studies explain several factors underlying students' satisfaction with their study abroad experience in Japan, more research is needed on the objectives of international students in study abroad programs in order to develop courses and curricula that meet their expectations. By identifying these objectives and analyzing the factors that contribute to making the study abroad experience more satisfying for international students in Japan, this paper attempts to fill this gap in the literature.

\section{The Japanese Government's Initiatives for Attracting International Students}

In Japan, the national government has played an important role in driving the internationalization of higher education institutes (Takagi, 2016; Yonezawa, 2011,). In fact, the Japanese government has launched several initiatives over the last decades to raise the number of international students, foreign nationals who study at a Japanese university, graduate school, college, or Japanese 
language school on a 'college student' visa. Among these initiatives, the 300,000 International Students Plan was implemented in 2008 with the goal of reaching 300,000 international students by the year 2020 as part of a global strategy to open up Japan to the rest of the world and expand flows of people, goods, money and information between Japan and other regions (MEXT, 2008). Together with this plan, the Global 30 project was launched in 2009 as a five-year funding project for internationalizing 30 designated core universities. Although only 13 universities were finally chosen (seven public and six private), these schools have been increasing the number of degree programs offered in English, and participating in promotional events and public relations activities outside Japan in an effort to attract potential overseas students. The initiatives under the Global 30 project have proved to be relatively effective, as the number of international students at the core universities increased every year, growing by more than $40 \%$ during a five-year period (Hennings \& Mintz, 2015). With the end of the Global 30 project in 2014, the government launched the Top Global University Project, a 10-year funding project for selected universities that aim to either enter the top 100 universities in world rankings or become front runners of internationalization in Japan. Universities funded by the program are required to increase lectures in English and improve the ratios of foreign faculty and students (MEXT, 2014). Accordingly, the program is likely to contribute to the growing numbers of international students in Japan, although the government's target of 300,000 international students by 2020 is unlikely to be achieved, as only about 170,000 were studying in Japan at higher education institutes in 2016 (Jasso, 2017).

While the rising number of international students has helped increase Japan's access to global human capital, international students have not brought substantial financial benefits to universities. As Lassegard (2016) points out, most students from developing countries in Asia, who are the majority of international students admitted to Japanese universities, find it very difficult to live and study in Japan without support from the Japanese government or their universities, and in some cases $95 \%$ of international students pay no tuition or fees to their university. Nevertheless, the presence of international students and related programs also attracts Japanese students who want to receive a more international education, thereby helping cover the financial burden of hosting the international students. Furthermore, partnerships with universities outside Japan create opportunities for domestic students to study abroad, which has emerged as a serious issue amid a growing-inward looking tendency of Japanese youth. To combat this tendency, the government has established several funding projects for the purpose of sending more Japanese students abroad and fostering human resources that can take on challenges in global settings, in an effort to bolster Japan's global competitiveness and enhance its ties with other countries (MEXT, 2012). Consequently, Japanese universities have been forming more overseas university partnerships through formal student exchange agreements. This has helped qualitatively enhance short-term study abroad programs aimed at attracting international students from partner universities, especially from those in English-speaking countries, a major study destination for Japanese students. Although students subject to exchange agreements are not required to pay tuition and fees for such programs, Japanese universities benefit from the opportunities to send more Japanese students abroad. In this context, the university selected for the survey in this paper has declared the goal of having the highest annual number of students sent abroad to study under partnership agreements among all universities in Japan. To achieve that goal, it will be even more important for its short-term study abroad programs to meet the expectations of students coming from partner universities, since increasing their numbers will also lead to more opportunities for Japanese students to study abroad. 


\section{RESEARCH METHOD}

To identify the objectives of international students, we conducted a survey at a private university in the Kansai region, which has been selected as a leading university under the Top Global University Project. The school has implemented a short-term study abroad program called the Contemporary Japan Program to attract students from partner universities to study in Japan for one or two semesters. The program was specially designed for incoming exchange students from a network of over 140 partner universities in 36 countries around the world. The majority of these students comes from Europe (36.7\%), followed by East/Southeast Asia (28.1\%), North America (27.3)\% and Australia/New Zealand (7\%), studying in a huge variety of study programs mainly in humanities, social science and business administration.

Exchange students are offered a choice between two study tracks: the Japanese Language Track for students with prior knowledge of Japanese, which focuses on Japanese language education and includes elective classes on Japanese culture and society; and the Modern Japan Track for students without any prior knowledge of Japanese, which offers classes on contemporary Japan taught in English and elective Japanese language classes. The students can also select other courses on contemporary Japan covering a variety of topics, such as politics, economics, and pop culture, and can choose from a wide selection of other English-mediated courses offered by the university.

To assess whether this short-term study abroad program meets the expectations of international students and provides them with a satisfying study abroad experience, we conducted a survey targeting 165 international students enrolled in the program. Among the 165 students targeted, 131 returned their questionnaires, of which 36 were enrolled in the Modern Japan Track and 95 in the Japanese Language Track, roughly corresponding to the ratio of total enrollment in each track.

Students were asked in the questionnaire to rank 11 given objectives for studying in Japan using Radio Button Grid questions. The button grid included questions on academic objectives, such as acquiring Japanese language skills and learning an academic discipline, and nonacademic objectives, such as gaining the experience of living in Japan and meeting new people and friends. The students could also write down additional study objectives besides the ones listed, but only six students made use of this option. Among them, two students named "traveling in Japan" as an objective, while the other four added "live in Asia," "a photography project," "Japanese food" and "be international," respectively, as other study objectives. Therefore, we believe that the 11 objectives listed in the questionnaire covered the vast majority of objectives pursued by the international students.

Respondents were asked to mark how important those objectives are to them as study objectives in Japan on a scale from one to four, with one representing "not at all important" and four "very important." For the analysis, an objective was considered as important if it was selected as either the highest (four) or second highest (three) rating in the scale. Next, we asked students to evaluate the degree to which they had achieved the objectives during their time in the program on a scale of one to four, with one representing "not at all" and four "completely achieved." For the analysis, an objective was considered to have been achieved if it was selected as either the highest (four) or second highest (three) rating in the scale. Finally, students were asked to assess which classes and activities offered in the Contemporary Japan Program helped them achieve these objectives, and how satisfied they were with their study abroad experience 
on a scale from one to four, with one representing "not at all satisfied" and four "very much satisfied."

Based on the survey results, we first analyzed how important the study objectives were for students studying in Japan and to what degree the objectives were achieved. To assess whether an important study objective was achieved to a high degree, we conducted a Wilcoxon signedrank test and compared the medians between the variables importance of study objectives and achievement of study objectives. The calculated p-values show whether an important study objective had been significantly achieved, with a p-value below 0.05 indicating that the objective had not been achieved. The calculated r-values show the difference between importance and achievement, with a higher negative r-value indicating a stronger difference between importance and achievement. Secondly, we examined how the level of achievement influenced students' satisfaction with their study abroad experience by analyzing the correlations between the variables achievement of study objectives and satisfaction with the study abroad experience, using the Kendall-tau correlation coefficient. Since results were expected to differ significantly between students in the Japanese Language Track (JLT) and Modern Japan Track (MJT), we separated the results by track. Although the findings are limited to the observed university program, we believe that our study will be useful as a bench mark for other universities who have similar short-term study abroad programs to attract international students.

\section{RESULTS}

\section{Objectives of International Students Enrolled in Study Abroad Programs}

Table 1 shows the 11 study objectives and the percentage of students who regarded them as important. Among the MJT students, 97\% regarded the "experience of living in Japan" as important, and 94\% considered "understanding Japanese society and culture" to be important. Among the JLT students, these two objectives were considered to be important by $92 \%$ and $90 \%$, respectively. The objective considered as important by the most JLT students was "Japanese language skills," which was regarded as important by only about half of the students in the MJT group. Given the different focus of each track, it is understandable that most students with prior knowledge of Japanese would evaluate improving their language skills as important, whereas most students with no or very little Japanese language ability would want to experience Japan and understand its culture and society. Meanwhile, "cross-cultural skills" and "meeting new people and making friends" were regarded as important by $86 \%$ and $83 \%$ of the MJT students," respectively, whereas $86 \%$ of JLT students chose "communication skills" as important, reflecting the importance they placed on studying the local language.

At the same time, far fewer students in both tracks selected the study objectives of "understanding your academic discipline" and "understanding Asian society and culture" as important, indicating the priority they gave to experiencing life in Japan over simply studying an academic subject, and their desire to learn about Japan rather than other countries in Asia. Moreover, comparatively fewer students considered "problem-solving skills" and "career development and future employability" as important objectives for studying in Japan, whereas high percentages of the students gave importance to "personal development," which includes self-awareness and self-confidence. In other words, many of the students did not expect to enhance their career opportunities or problem-solving skills in Japan but expected to develop personally during their stay abroad. 
Table 1: Percentages of International Students Rating Study Objectives as Important

\begin{tabular}{lcc}
\hline Study objectives (N=131 Total) & $\begin{array}{c}\text { Percentage } \\
\text { of MJT } \\
\text { students } \\
(\mathrm{N}=36)\end{array}$ & $\begin{array}{c}\text { Percentage of } \\
\text { JLT students } \\
(\mathrm{N}=95)\end{array}$ \\
\hline 1. Japanese language skills & $56 \%$ & $95 \%$ \\
2. Understanding your academic discipline & $50 \%$ & $63 \%$ \\
3. Understanding Japanese society and culture & $94 \%$ & $90 \%$ \\
4. Understanding Asian society and culture & $67 \%$ & $58 \%$ \\
5. Experience of living in Japan & $97 \%$ & $92 \%$ \\
6. Career development \& future employability & $61 \%$ & $58 \%$ \\
7. Personal development (e.g. self-confidence) & $81 \%$ & $81 \%$ \\
8. Cross-cultural skills & $86 \%$ & $80 \%$ \\
9. Problem-solving skills & $53 \%$ & $65 \%$ \\
10. Communication skills & $80 \%$ & $86 \%$ \\
11. Meeting new people and making friends & $83 \%$ & $79 \%$ \\
\hline
\end{tabular}

Note. $M J T=$ Modern Japan Track, $J L T=$ Japanese Language Track

\section{Achievement of the Study Objectives}

Tables 2 and 3 show the degree to which the students had achieved the 11 study objectives during their time in the program. Beginning with the MJT students, $92 \%$ answered that the objective of "experience of living in Japan" was achieved. Accordingly, the calculated p-value of 0.218 shows no significant statistic difference between the level of importance and the level of achievement, meaning that students who answered that the experience of living in Japan is an important study objective were also highly likely to have also achieved it. This result is also in line with the rvalue of -0.205 , which indicates only a weak negative correlation between the percentage of students who regarded the objective as important (97\%) and the percentage who achieved it $(92 \%)$. Moreover, no significant statistical differences between the level of importance and achievement were found for the objectives of "understanding Japanese society and culture," "cross-cultural skills" and "meeting new people and making friends," indicating that those objectives had been achieved.

Although the four most commonly pursued study objectives could be achieved by a high percentage of the MJT students, the objectives of "personal development," "communication skills," "Japanese language skills" and "career development and future employability" were not achieved to the same degree. In fact, the respective p-values show strong statistical differences between the level of importance and level of achievement, and negative r-values are higher for those objectives. This demonstrates that a considerable portion of the students who regarded those study objectives as important could not achieve them at a high level.

Among all of the study objectives, the lowest p-value and highest negative effect size was for the objective of gaining Japanese language skills. Given the fact that just over half of the MJT students consider Japanese language skills as important, however, the difference between importance and achievement is not as relevant in comparison with the JLT students. As shown in Table 3, 95\% of JLT students regarded this objective as important and $74 \%$ stated they 
achieved it, resulting in a p-value of 0.000 and an effect size of -0.681 . This demonstrates that a considerable portion of students who considered Japanese language skills as important could not sufficiently gain these skills.

Table 2: Percentages of Modern Japan Track Students Who Achieved Study Objectives $(N=36)$

\begin{tabular}{|c|c|c|c|c|}
\hline \multirow[t]{2}{*}{ Study objectives ranked by importance } & \multirow{2}{*}{$\begin{array}{c}\text { Students } \\
\text { stating } \\
\text { importance of } \\
\text { objective }\end{array}$} & \multirow{2}{*}{$\begin{array}{l}\text { Students } \\
\text { who } \\
\text { achieved } \\
\text { objective }\end{array}$} & \multicolumn{2}{|c|}{$\begin{array}{l}\text { Wilcoxon signed- } \\
\text { rank test results }\end{array}$} \\
\hline & & & p-value & $\begin{array}{c}\text { r- } \\
\text { value }\end{array}$ \\
\hline 1. Experience of living in Japan & $97 \%$ & $92 \%$ & 0.218 & -0.205 \\
\hline $\begin{array}{l}\text { 2. Understanding Japanese society and } \\
\text { culture }\end{array}$ & $94 \%$ & $92 \%$ & 0.073 & -0.299 \\
\hline 3. Cross-cultural skills & $86 \%$ & $81 \%$ & 0.110 & -0.266 \\
\hline $\begin{array}{l}\text { 4. Meeting new people and making } \\
\text { friends }\end{array}$ & $83 \%$ & $80 \%$ & 0.282 & -0.179 \\
\hline $\begin{array}{l}\text { 5. Personal development (e.g. self- } \\
\text { confidence) }\end{array}$ & $81 \%$ & $69 \%$ & 0.006 & -0.456 \\
\hline 6. Communication skills & $80 \%$ & $67 \%$ & 0.035 & -0.351 \\
\hline $\begin{array}{l}\text { 7. Understanding Asian society and } \\
\text { culture }\end{array}$ & $67 \%$ & $69 \%$ & 0.311 & -0.168 \\
\hline $\begin{array}{l}\text { 8. Career development and future } \\
\text { employability }\end{array}$ & $61 \%$ & $39 \%$ & 0.008 & -0.445 \\
\hline 9. Japanese language skills & $56 \%$ & $39 \%$ & 0.005 & -0.466 \\
\hline 10. Problem-solving skills & $53 \%$ & $53 \%$ & 0.695 & -0.065 \\
\hline $\begin{array}{l}\text { 11. Understanding your academic } \\
\text { discipline }\end{array}$ & $50 \%$ & $40 \%$ & 0.320 & -0.165 \\
\hline
\end{tabular}

Among the JLT students, the differences were much smaller for the study objectives of "experience of living in Japan," "understanding Japanese society and culture" and "communication skills." A high percentage of the students considered these study objectives as important and successfully achieved them. In contrast, results of the Wilcoxon signed-rank test show significant differences between the objectives of "understanding Japanese society and culture" and "communication skills," with p-values of 0.016 and 0.002 , respectively. This reflects the fact that most JLT students selected the highest rank in the scale of importance but only the second highest rank in the scale of achievement, suggesting that their achievements fell short of the significance they gave to the respective objectives. This is particularly apparent for the objective of "communication skills," for which the r-value was -0.319 , similar to the figure for the same objective in the MJT group. Given the low level of achievement for "Japanese language skills," it is also understandable that "communication skills" could not be achieved to the expected levels by students in both groups.

To assess which classes and activities offered in the Contemporary Japan Program had an influence on these results, we asked students in each track whether certain classes and activities were helpful for achieving their study objectives, as shown in Figure 1. While the 
majority of MJT students selected residential life (e.g. providing housing opportunities, arranging home stays) and Japan studies classes as helpful, most JLT students regarded Japanese Language classes and the Nihongo Partner buddy program as helpful for achieving their objectives.

Table 3: Percentages of Japanese Language Track Students Who Achieved Study Objectives $(N=95)$

\begin{tabular}{|c|c|c|c|c|}
\hline \multirow{2}{*}{ Study objectives ranked by importance } & \multirow{2}{*}{$\begin{array}{c}\text { Students } \\
\text { stating } \\
\text { importance of } \\
\text { objective }\end{array}$} & \multirow{2}{*}{$\begin{array}{l}\text { Students } \\
\text { who } \\
\text { achieved } \\
\text { objective }\end{array}$} & \multicolumn{2}{|c|}{$\begin{array}{l}\text { Wilcoxon signed- } \\
\text { rank test results }\end{array}$} \\
\hline & & & $\mathrm{p}$-value & r-value \\
\hline 1. Japanese language skills & $95 \%$ & $74 \%$ & 0.000 & -0.681 \\
\hline 2. Experience of living in Japan & $92 \%$ & $94 \%$ & 0.509 & -0.068 \\
\hline $\begin{array}{l}\text { 3. Understanding Japanese society and } \\
\text { culture }\end{array}$ & $90 \%$ & $87 \%$ & 0.016 & -0.248 \\
\hline 4. Communication skills & $86 \%$ & $81 \%$ & 0.002 & -0.319 \\
\hline $\begin{array}{l}\text { 5. Personal development (e.g. self- } \\
\text { confidence) }\end{array}$ & $81 \%$ & $75 \%$ & 0.001 & -0.326 \\
\hline 6. Cross-cultural skills & $80 \%$ & $79 \%$ & 0.112 & -0.163 \\
\hline $\begin{array}{l}\text { 7. Meeting new people and making } \\
\text { friends }\end{array}$ & $79 \%$ & $80 \%$ & 0.782 & -0.028 \\
\hline 8. Problem-solving skills & $65 \%$ & $58 \%$ & 0.091 & -0.173 \\
\hline $\begin{array}{l}\text { 9. Understanding your academic } \\
\text { discipline }\end{array}$ & $63 \%$ & $45 \%$ & 0.000 & -0.364 \\
\hline $\begin{array}{l}\text { 10. Career development and future } \\
\text { employability }\end{array}$ & $58 \%$ & $32 \%$ & 0.000 & -0.508 \\
\hline $\begin{array}{l}\text { 11. Understanding Asian society and } \\
\text { culture }\end{array}$ & $58 \%$ & $54 \%$ & 0.352 & -0.096 \\
\hline
\end{tabular}

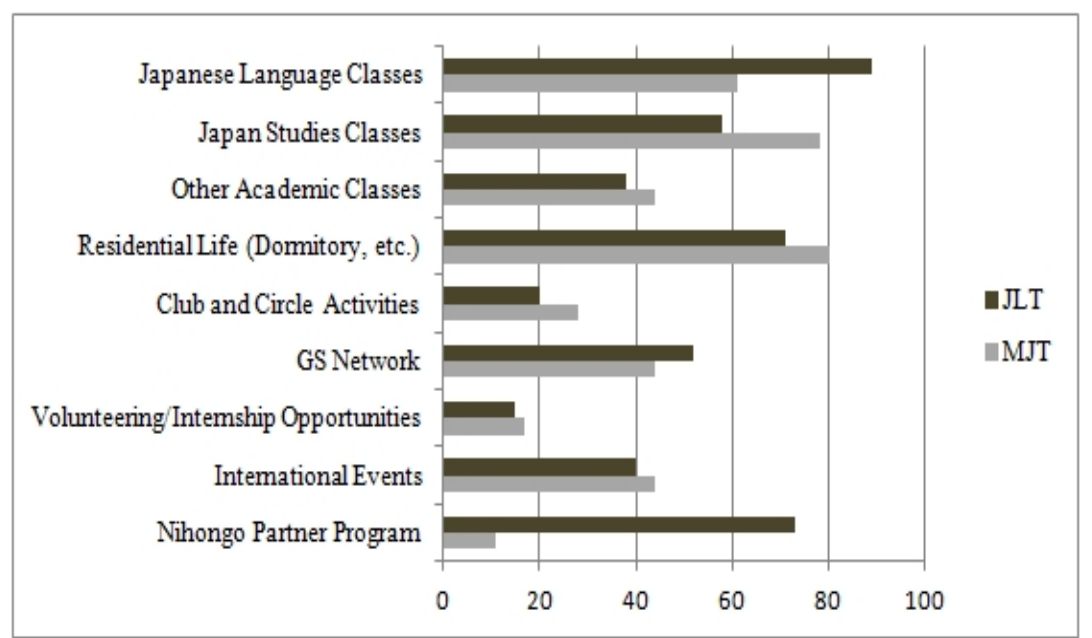

Figure 1: Classes and Activities that Helped Students Achieve Their Study Objectives (Percentage of Students Who Answered Very Helpful or Helpful, $N=131$ )

Note. $J L T=$ Japanese Language Track, $M J T=$ Modern Japan Track 
These results suggest that the reason for not achieving Japanese language and communication skills to the degree expected was not due to a lack of classes or poor quality of the classes. We could surmise, therefore, that the low achievement of Japanese skills stemmed from the challenges of mastering such a difficult language in the given time. We assume that this is also a reason why students in both tracks did not achieve the objective of "personal development" to such a high degree, since limited language skills would make it harder for them to successfully deal with a foreign environment. In this context, students at the university benefited from extracurricular activities such as the Nihongo Partner buddy program and the GS Network, which is a group of Japanese students who help international students with everyday life and organize various intercultural events.

\section{Satisfaction with the Study Abroad Experience}

In total, the majority of students surveyed indicated a satisfying study abroad experience during their time in Japan. Among MJT students, 52.8\% answered they were "very satisfied" and 41.7\% selected "mostly satisfied," meaning over $94 \%$ were satisfied overall with their study abroad experience. In comparison, the JLT students were slightly less satisfied, with $54.7 \%$ selecting "very satisfied" and $34.7 \%$ choosing "mostly satisfied," for a combined total of $89.4 \%$. Table 4 shows which of the 11 study objectives had the biggest effect on the students' satisfaction with their study abroad experience in Japan.

Table 4: Correlation between Achievement of Study Objectives and Satisfaction with the Study Abroad Experience in Japan $(N=131)$

\begin{tabular}{lll}
\hline & $\begin{array}{l}\text { Satisfaction } \\
\text { with study } \\
\text { abroad } \\
\text { experience MJT } \\
\text { students (N=36) }\end{array}$ & $\begin{array}{l}\text { Satisfaction } \\
\text { with study } \\
\text { abroad } \\
\text { experience JLT } \\
\text { students } \\
\text { (N=95) }\end{array}$ \\
\hline Japanese language skills & $0.454^{* *}$ & $0.544^{* *}$ \\
Understanding your academic discipline & -0.037 & 0.034 \\
Understanding Japanese society and culture & $0.353^{* *}$ & $0.311^{* *}$ \\
Understanding Asian society and culture & 0.145 & 0.116 \\
Experience of living in Japan & $0.463^{* *}$ & $0.339^{* *}$ \\
Career development and future employability & $0.354^{*}$ & $0.184^{*}$ \\
Personal development (e.g. self-confidence) & $0.388^{* *}$ & $0.287^{* *}$ \\
Cross-cultural skills & $0.364^{*}$ & 0.146 \\
Problem-solving skills & $0.400^{* *}$ & 0.090 \\
Communication skills & $0.422^{* *}$ & $0.288^{* *}$ \\
Meeting new people and making friends & $0.401^{* *}$ & $0.388^{* *}$ \\
\hline
\end{tabular}

Note. ${ }^{* *}=\mathrm{p}$-value significant at the 0.01 level; $*=\mathrm{p}$-value significant at the 0.05 level, $M J T=$ Modern Japan Track, $J L T=$ Japanese Language Track 
Most strongly correlated with satisfaction for both groups of students was the study objective of "Japanese language skills", with results of 0.454 for MJT and 0.544 for JLT students. This indicates that the more students improve their Japanese ability, the more satisfied they become with their study abroad experience. This is particularly interesting in the case of the MJT group. While almost all JLT students regarded Japanese language skills as an important study objective, only about half of the students in the MJT group considered that objective as important. Nevertheless, acquiring Japanese language skills has a substantial influence on the overall satisfaction of the MJT students with their study abroad experience. This was also the case for the objectives, "understanding Japanese society and culture," "experience of living in Japan," and "meeting new people and making friends," for which correlations exceeded 0.3 for both groups. No significant correlations were found with respect to the objectives of "understanding Asian society and culture" and "understanding your academic discipline," indicating that students in both groups came to Japan mainly for the purpose of living in the country rather than studying their discipline or learning about Asia in general. Consequently, achieving these objectives has no influence on students' satisfaction.

Overall, significant correlations between the achievement of study objectives and satisfaction with the study abroad experience were more frequent and stronger in the MJT group. While JLT students were mostly satisfied upon achieving Japanese language skills, the achievement of communication and cross-cultural skills was a major factor for the satisfaction of MJT students. Given the fact that the MJT students focus on English-mediated classes about contemporary Japan and not on language education, it is understandable that they would be motivated to achieve those skills in order to overcome the language barrier they experience in their everyday life in Japan. In a survey conducted among international students without Japanese language proficiency, Hiratsuka (2016) found that such students even face obstacles in accessing all of the resources provided by their university due to a lack of Japanese language skills. According to our survey results, satisfaction among MJT students was substantially influenced by the achievement of communication skills and cross-cultural skills, with correlations of 0.422 and 0.364 , respectively. In contrast, among JLT students, who already had some degree of Japanese language proficiency, satisfaction was weakly related to achieving communication skills and unrelated to gaining cross-cultural skills. These results show that it is important to differentiate between international students with and without Japanese language proficiency when developing programs that aim to provide a satisfying study abroad experience.

\section{DISCUSSION AND CONCLUSION}

Regardless of academic background, the reasons why students go to Japan to study include experiencing life in Japan, understanding its society and culture, learning the language, and meeting new people and making friends. Accordingly, programs designed for international students should focus on these needs and provide students with opportunities for deeply experiencing Japan, including classes on Japanese language, society and culture. As pointed out by Tamaoka et al. (2003), curriculum provided by Japanese universities must match the students' purposes of learning. In this regard, our survey results suggest that the observed Contemporary Japan Program provides a suitable curriculum for international students, and may serve as a benchmark for other universities with similar short-term study abroad programs. It is important, however, that such programs pay close attention to the difference between students who have or do not have Japanese language skills. As our correlation analysis has shown, achieving cross- 
cultural and communication skills was a major factor for having a satisfying study abroad experience among students who lacked Japanese language proficiency. Accordingly, universities should offer comprehensive Japanese language classes to all international students in addition to promoting non-academic activities that meet their expectations. As argued by Sato (2011), the quality of Japanese language classes and participation in activities such as field trips are of great importance for international students in Japan. Therefore, such students should be given opportunities to participate in non-academic programs in order to experience life in Japan and interact with local students and citizens. Survey results for both groups of students have shown that there is a considerable gap between importance and achievement when it comes to Japanese language and communication skills. Thus, exposure to community life is crucial for reducing this gap and helping students improve their cross-cultural skills. In addition, this exposure can also benefit their personal development by fostering the self-confidence that comes with successfully mastering a foreign environment. In essence, short-term study abroad programs that aim to meet students' expectations should address their different study objectives and offer a combination of academic and non-academic activities that cater to the needs of the international student body.

\section{Acknowledgement}

This research was supported by a research grant from the Center for the Study of Higher Education at Kwansei Gakuin University, Japan.

\section{REFERENCES}

Agarwal, P., Said, M.E., Sehoole, M.T., Sirozi, M., \& De Wit, H. (2008). The dynamics of international student circulation in a global context: Summary, conclusions and recommendations. In H. De Wit, P. Agarwal, M.E. Said, M.T. Sehoole \& M. Sirozi, (Ed.), The dynamics of international student circulation in a global context (233-261). Rotterdam: Sense Publishers.

Aleles, J. (2015). Japan's Global 30 Program: The push and pull factors of international student mobility. International Journal of Learning, Teaching and Educational Research, 13(2), 55-65.

Asare-Nuamah, P. (2017). International students' satisfaction: Assessing the determinants of satisfaction. Higher Education for the Future, 4(1), 44-59.

Caruso, R., \& De Wit, H. (2015). Determinants of mobility of students in Europe: Empirical evidence for the period 1998-2009. Journal of Studies in International Education, 19(3), 265-282.

Choudaha, R., \& de Wit, H. (2014). Challenges and opportunities for global student mobility in the future: A comparative and critical analysis. In B. Streitwieser (Ed.), Internationalisation of Higher Education and Global Mobility (19-33). Oxford, UK: Symposium Books.

Hennings, M., \& Mintz, S. (2015). Japan's measures to attract international students and the impact of student mobility on the labor market. Journal of International and Advanced Japanese Studies, 7, 243-251.

Hiratsuka, H. (2016). Japanese language as an organizational barrier for international students to access to university services: A case of Aoyama Gakuin University. Journal of International Students, 6(4), 956-966.

JASSO, Japan Student Services Organization (2017). Result of an Annual Survey of International Students in Japan 2016. Retrieved from http://www.jasso.go.jp/en/

Jon, J. E., \& Kim, E.Y. (2011). What it takes to internationalize higher education in Korea and Japan: English-mediated courses and international students. In J.D. Palmer, A. Roberts, Y.H. Cho \& G.S. Ching (Ed.), The Internationalization of East Asian Higher Education. Globalization's Impact (147-171). New York, NY: Palgrave Macmillan. 
Lassegard, J. (2016): Educational diversification strategies: Japanese universities' efforts to attract international students. In C. C. Ng, R. Fox \& M. Nakano (Ed.), Reforming learning and teaching in Asia-Pacific universities. Berlin: Springer, 47-75.

Mazzarol, T. \& Soutar, G. (2002). 'Push-pull' factors influencing international student destination choice. International Journal of Educational Management, 16, 82-90.

MEXT, Ministry of Education, Culture, Sports, Science and Technology (2008).

Outline of the Student Exchange System. Study in Japan and Abroad. Retrieved from http://www.mext.go.jp/a_menu/koutou/ryugaku/081210/001.pdf

MEXT. (2012). Selection for the FY2012 Project for Promotion of Global Human Resource Development. Retrieved from http://www.mext.go.jp/en/policy/education/

MEXT. (2014). Selection for the FY 2014 Top Global University Project. Retrieved from http://www.mext.go.jp/b_menu/houdou/26/09/_icsFiles/afieldfile/2014/10/07/1352218_02.pdf (last accessed: 2017-08-22).

Perez-Encinas, A., \& Rodriguez-Pomeda, J. (2018). International students' perceptions of their needs when going abroad: Services on demand. Journal of Studies in International Education, 22(1), 20-36.

Sato, Y. (2011). Nihon no tanki ryūgaku no nīzu to kadai ni kansuru kōsatsu - tanki ryūgakusei chōsa no chiiki betsu, kikan betsu, katei-betsu bunseki kara [The Needs and Problems of Short-term Exchange in Japan: A Questionnaire Analysis of Short-term Exchange Students According to Their Regions, Study Period and Courses]. Ryūgakusei Kyōiku, 16, 13-24.

Shimauchi, S. (2014). Naze, eigo puroguramu ni ryūgaku suru no ka? Nikkan kōtō kyōiku ryūgaku ni okeru pusshu puru yōin no shitsuteki bunseki o tōshite [Why Are Students Studying Abroad at EnglishMedium Degree Programs in Non-English Speaking Countries?Kyōiku Shakaigaku, 94, 303-324.

Takagi, H. (2016). Transformation of Japanese Universities through the Process of Internationalization. A comparative perspective with Anglo-Saxon universities. In J.E. Côté \& A. Furlong (Ed.), Routledge Handbook of the Sociology of Higher Education (262-272). New York, NY: Routledge,

Tamaoka, K., Ninomiya, A., \& Nakaya, A. (2003). What makes international students satisfied with a Japanese university? Asia Pacific Education Review, 4(2), 119-128.

Yonezawa, A. (2011). the internationalization of Japanese higher education: Policy debates and realities. In S. Marginson, S. Kaur \& E. Sawir (Ed.), Higher education in the Asia-Pacific: Strategic responses to globalization (329-342). London, UK: Springer.

MATTHIAS HENNINGS, $\mathrm{PhD}$, is an associate professor at the Center for International Education and Collaboration (CIEC) at Kwansei Gakuin University in Japan. Email: matthias.hennings@kwansei.ac.jp

SHIN TANABE is an associate professor at the Center for International Education and Collaboration (CIEC) at Kwansei Gakuin University in Japan. Email: shintanabe@gmail.com 